\title{
Fatigue Failure of a 2500-Ton Forge Press
}

\author{
Nicoli Ames $\cdot$ Joseph Lemberg $\cdot$ Robert Caligiuri
}

Submitted: 9 November 2016/Published online: 19 December 2016

(C) The Author(s) 2016. This article is published with open access at Springerlink.com

\begin{abstract}
Large industrial equipment can fail spectacularly, and analyzing the failure can prove difficult, as catastrophic failures can provide red herrings that confound the failure analysis. One such case involved the fatigue failure of a 2500-ton forge press. During operation, two tie rods failed, leading to catastrophic failure of the press. During post-mortem analysis, several fatigue cracks were found in the upper platen of the forge press and misalignment of some of the tie rod nuts was observed. Finite element modeling revealed that the presence of the platen fatigue cracks and the misaligned nuts had little effect on the fatigue behavior of the press. Instead, the high strength of the two failed tie rods led to higher-than-intended service stresses in these tie rods and resulted in a reduced fatigue life.
\end{abstract}

Keywords Catastrophic failure - Failure analysis · Fatigue failure · Finite element analysis - Fatigue analysis . Steel

N. Ames

Exponent, Inc., 1331 17th Street, Suite 515, Denver, CO 80202, USA

J. Lemberg $(\bowtie)$

Exponent, Inc., 3350 Peachtree Road NE, Suite 1125, Atlanta,

GA 30326, USA

e-mail: jlemberg@exponent.com

R. Caligiuri

Exponent, Inc., 149 Commonwealth Drive, Menlo Park,

CA 94025, USA

\section{Background}

A 2500-ton cogging press failed catastrophically after approximately 8 months in service. Two of the four tie rods comprising the forge press broke during operation (SW and $\mathrm{SE}),{ }^{1}$ leading to substantial damage to the entire forge. A third tie rod (NW) was reportedly cracked but did not fail. The fourth tie rod exhibited no sign of cracking (NE). A photograph of the subject forge press is shown in Fig. 1. At its most basic structure, the forge press comprises a fixed upper platen, a fixed lower platen, and a moving platen that supplies the forging load. The forge press is held together by the four tie rods, which are pre-tensioned using hydraulic nuts.

During a post-mortem inspection, cracks were identified in a number of welds in the upper platen. The location and size of these cracks were included in our finite element model (FEM) to probe what role, if any, they may have played in the stress distribution within the tie rods and thus ultimately in the catastrophic failure of the forge press. Similarly, misalignment of the hydraulic nut seats on the upper platen was observed post-mortem. Misalignment of the hydraulic nuts may have led to an increased bending stress in the tie rods.

To inform the FEM with mechanical properties of the actual, failed parts, mechanical and chemical testing was performed, as discussed below.

\footnotetext{
1 We adopt a nomenclature for these tie rods based on the orientation of the forge within the plant (i.e., NE, NW, SE and SW).
} 


\section{Chemical and Mechanical Testing}

Chemical analysis of the tie rods was performed in accordance with ASTM E352 [1], while the testing techniques described in ASTM E350 [2] were used to analyze the upper platen and center support tube materials. All

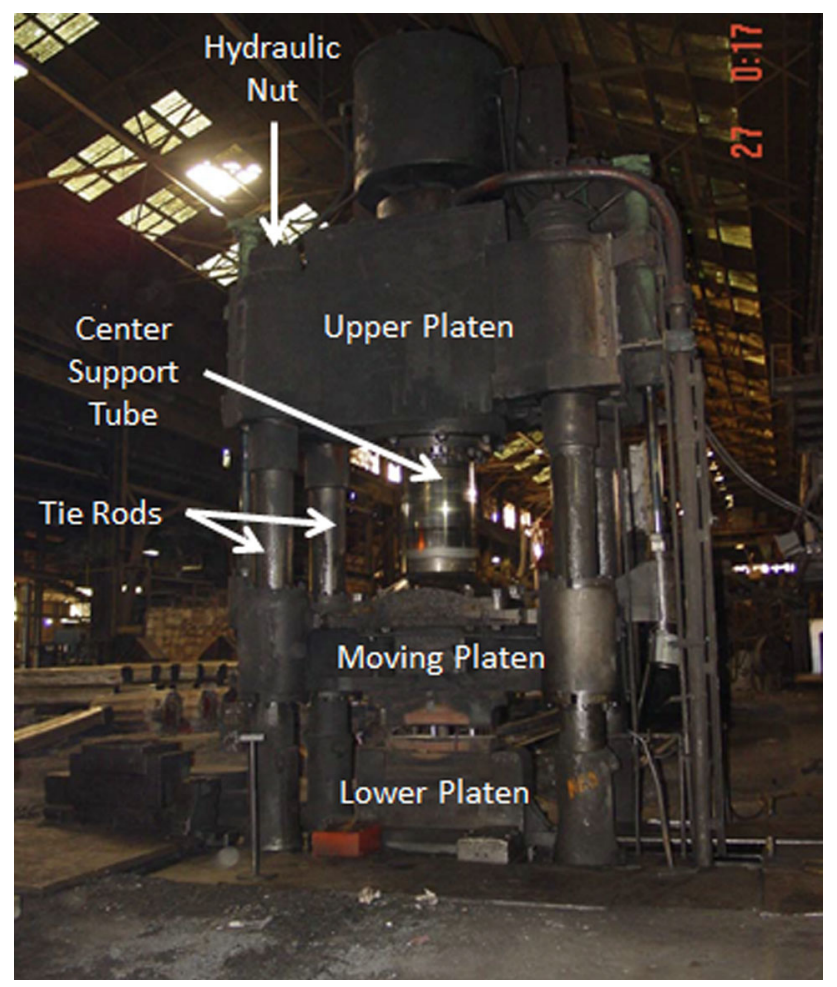

Fig. 1 2500-ton forge press. The upper and lower platens are fixed, while the moving platen applies the forging load. The center support tube drives the moving platen, and the tie rods complete the structural frame for the forge press. The tie rods are pre-tensioned with the hydraulic nuts materials met the alloy specifications. The tie rods satisfied the compositional requirements of AISI 4340, while the upper platen and center support tube satisfied the compositional requirements of ASTM A516 grade 70 [3] and ASTM A508 grade $4 \mathrm{~N}$ Class 3 [4], respectively.

Tension tests in accordance with ASTM E8 [5] were performed on all the materials. Axial, long-transverse and short-transverse samples were tested from the upper platen top plate, while axial samples alone were evaluated from the tie rods and the platen center support tube. Roomtemperature Charpy impact tests were performed on the upper platen top plate and each tie rod in accordance with ASTM E23 [6]. Axial and transverse orientations were evaluated for the tie rods, while three orientations were tested from the upper platen top plate. The tensile results for the tie rod materials were used in our FEM analysis.

\section{Finite Element Modeling}

A three-dimensional quarter-symmetry model of the forge press was constructed. The moving platen and connected center support tube were not explicitly modeled, but the loads resulting from the equivalent contact pressure from the moving platen at a 2500-ton load was included. Axisymmetric (i.e., non-helical) 9.875-3-BUTT-2 buttress threads were included in the tie rod and hydraulic nut geometries. The model was comprised of 571,039 reducedintegration hexahedral (C3D8R) elements. An image of the overall mesh and a close-up view of the upper platen mesh are shown in Fig. 2. An image of the tie rod/hydraulic nut mesh is shown in Fig. 3.

Mechanical properties used for the various materials are shown in Table 1 . Note that plastic hardening was
Fig. 2 Quarter-symmetric three-dimensional model of the forge press. Inset: close-up of the upper platen geometry. Mechanical properties of the color-coded materials used for the various components are provided in Table 1

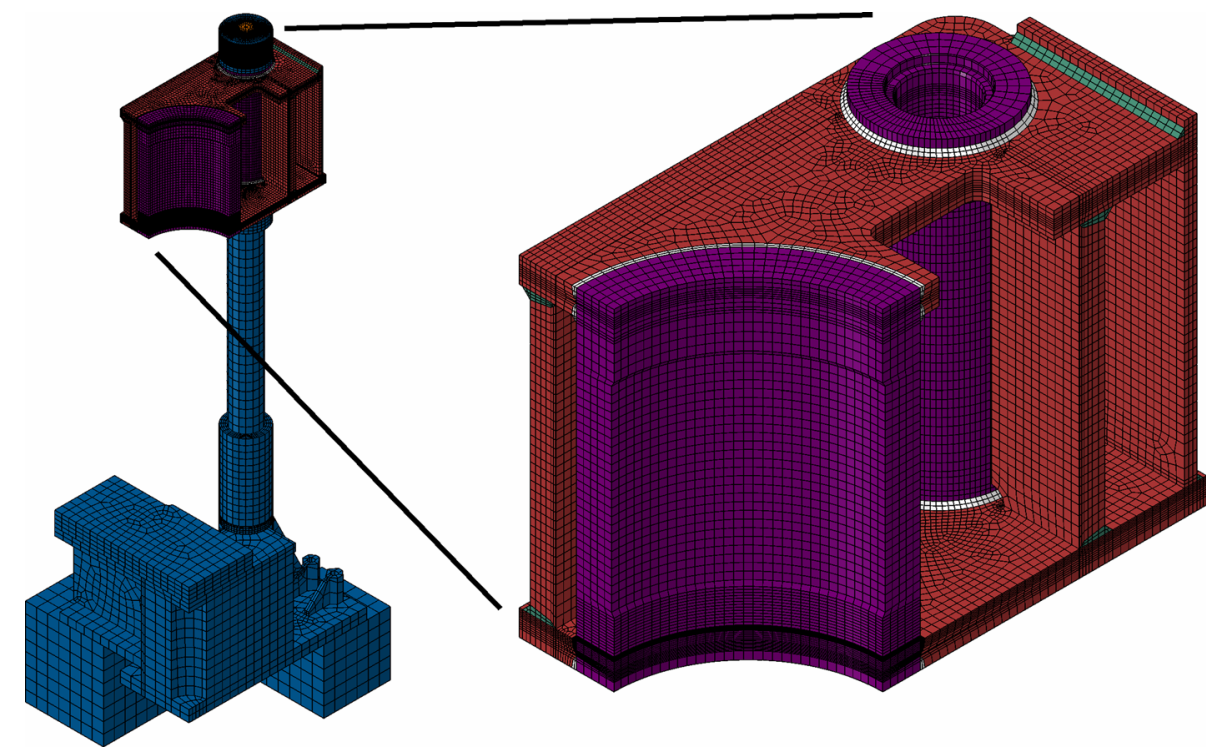


Fig. 3 FEM of the 9.8753 BUTT-2 threads included in the tie rod (orange) and hydraulic nut (blue) geometries. Inset: close-up of the buttress thread geometry

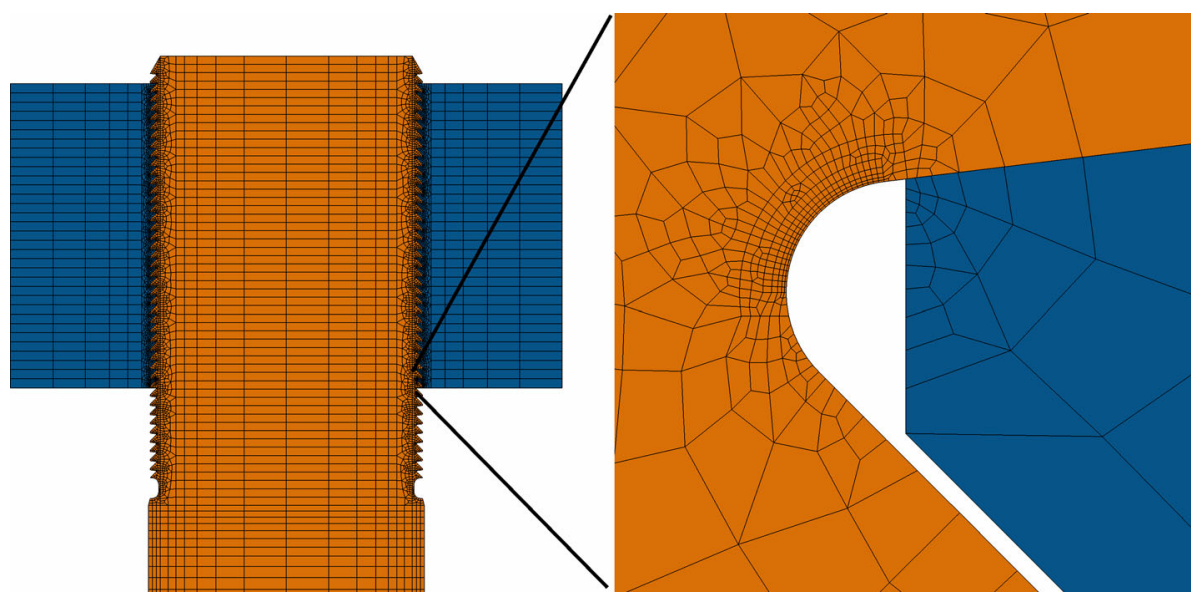

Table 1 Mechanical properties of the various materials comprising the finite element model

\begin{tabular}{|c|c|c|c|}
\hline Materials & $E(\mathrm{ksi})$ & $v$ & $\sigma_{\mathrm{Y}}(\mathrm{ksi})$ \\
\hline Blue regions (elastic) & 29,000 & .29 & $\ldots$ \\
\hline E71 welds (green) & 29,000 & .29 & 58 \\
\hline E110 welds (white) & 29,000 & .29 & 98 \\
\hline Tubes, A508 steel (purple) & 29,000 & .29 & 70 \\
\hline Plates, A516 steel (red) & 29,000 & .29 & 38 \\
\hline
\end{tabular}

Tie rod, 4340 steel (orange)

Min strength, NE tie rod

Max strength, SW tie rod
29,000

29,000
.29

.29
121

156

Both the softest (NE tie rod) and the hardest (SW tie rod) tie rods were modeled. The colors referenced in the table correspond to the colors shown in Fig. 4

accounted for in all the elastic-plastic materials. Material properties from two tie rods were used in the FEM: the lowest strength tie rod (NE, $121 \mathrm{ksi}$ ) which did not crack and the highest strength tie rod (SW, $156 \mathrm{ksi}$ ) which failed catastrophically. ${ }^{2}$ We note that the yield strength of the SW

\footnotetext{
$\overline{2}$ The yield strength values reported here and used throughout this analysis represent the lowest and highest single readings for the NE and SW tie rods, respectively.
}

tie rod is higher than the maximum specified ultimate tensile strength of the tie rods. As a result, this tie rod was out of specification. ${ }^{3}$

\footnotetext{
3 The SE tie rod, which was not modeled, was also out of specification regarding the maximum tensile strength. As the yield strength for this tie rod was lower than that of the SW tie rod, only the SW tie was modeled as a worst-case scenario. Both the SW and the SE tie rods failed catastrophically.
} 
To study the effects of a weld failure, a 24-inch crack (48-inch total length) was introduced into the quartersymmetric model at the location of a reported through-weld crack. The placement of the crack is shown schematically in Fig. 4. To simulate the intact weld, the two faces of the seam were bonded together in the model. The cracked weld was simulated by allowing the two faces to separate while contact was enforced. Measurements taken from the asbuilt hydraulic nut seats on the upper platen were included

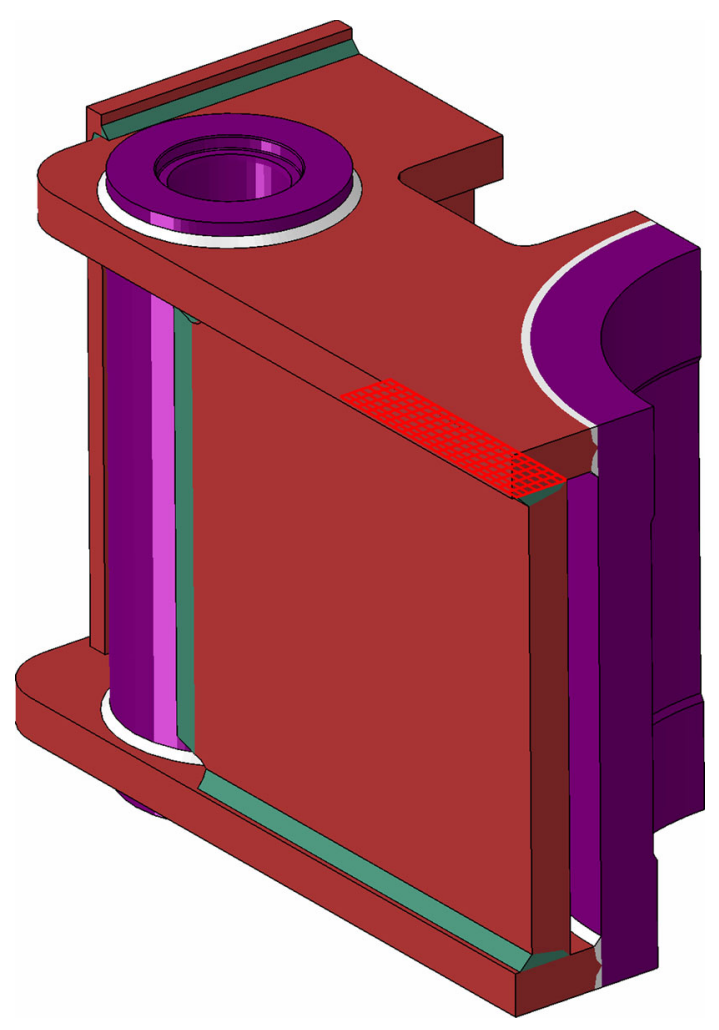

Fig. 4 Schematic close-up of the upper platen showing the placement of the weld crack within the model (red box) in the model to allow for misalignment of the hydraulic nut and the potential for bending stresses in the tie rods. Measurements for the NE and SW hydraulic nut seats were included in the respective models.

Loading was accomplished in the following fashion:

1. Apply tie rod preload of $868 \mathrm{kip}$,

2. Apply gravitational loading,

3. Apply piston load distributed over the face of the center column,

4. Remove piston load, and

5. Reapply piston load.

The cyclic load, equivalent to the contact pressure from the moving platen at a 2500-ton load, was $5.6 \mathrm{ksi}$.

\section{Results}

The results of the FEM analysis are shown in Table 2 below. Note that the reported peak Mises stress did not necessarily occur in the same location for every loading case. The cyclic mean stresses reported in Table 2 were taken from the locations of the peak cyclic alternating stresses.

FEM analysis of the root of the first engaged thread indicated no change in the stress state as a result of the modeled crack in the upper platen. Figures 5, 6, 7, and 8 show the calculated peak Mises, mean, and alternating stresses at the first engaged thread root for the SW Tie Rod (i.e., maximum strength) model. Similar results were obtained for the NE Tie Rod (i.e., minimum-strength case), though the calculated stresses were lower, consistent with the lower strength for this model.

As discussed above, measurements taken from the asbuilt hydraulic nut seats on the upper platen were included in the model to allow for misalignment of the hydraulic

Table 2 Summary of tie rod stresses

\begin{tabular}{|c|c|c|c|c|c|c|c|}
\hline \multirow[b]{2}{*}{$\begin{array}{l}\text { Tie rod } \\
\text { material }\end{array}$} & \multirow[b]{2}{*}{$\begin{array}{l}\text { Tie rod } \\
\text { preload }\end{array}$} & \multirow[b]{2}{*}{$\begin{array}{c}\text { Nut } \\
\text { interface }\end{array}$} & \multirow[b]{2}{*}{$\begin{array}{l}\text { Weld } \\
\text { status }\end{array}$} & \multicolumn{2}{|c|}{ Peak mises stress (ksi) } & \multirow[b]{2}{*}{$\begin{array}{c}\text { Cyclic mean stress } \\
(\mathrm{ksi})\end{array}$} & \multirow[b]{2}{*}{$\begin{array}{l}\text { Cyclic alternating stress } \\
(\mathrm{ksi})\end{array}$} \\
\hline & & & & $\begin{array}{l}\text { Piston load } \\
\text { applied }\end{array}$ & $\begin{array}{l}\text { Piston load } \\
\text { removed }\end{array}$ & & \\
\hline $\mathrm{NE}$ & 868 kip & Parallel & Intact & 128.1 & 83.2 & 86.4 & 42.1 \\
\hline $\mathrm{NE}$ & 868 kip & Parallel & Failed & 128.1 & 83.2 & 86.6 & 42.0 \\
\hline $\mathrm{NE}$ & 868 kip & Misaligned & Intact & 128.2 & 85.3 & 91.8 & 36.5 \\
\hline $\mathrm{NE}$ & $\sim 0$ kip & Parallel & Intact & 126.8 & 70.7 & 31.8 & 97.3 \\
\hline $\mathrm{NE}$ & $\sim 0$ kip & Parallel & Failed & 126.8 & 70.4 & 31.9 & 97.1 \\
\hline SW & 868 kip & Parallel & Intact & 160.5 & 104.2 & 118.3 & 42.1 \\
\hline SW & 868 kip & Parallel & Failed & 160.4 & 104.2 & 118.4 & 42.0 \\
\hline SW & 868 kip & Misaligned & Intact & 162.8 & 112.6 & 125.8 & 37.0 \\
\hline SW & $\sim 0$ kip & Parallel & Intact & 158.8 & 37.5 & 60.9 & 97.3 \\
\hline SW & $\sim 0$ kip & Parallel & Failed & 158.8 & 37.3 & 61.0 & 97.2 \\
\hline
\end{tabular}



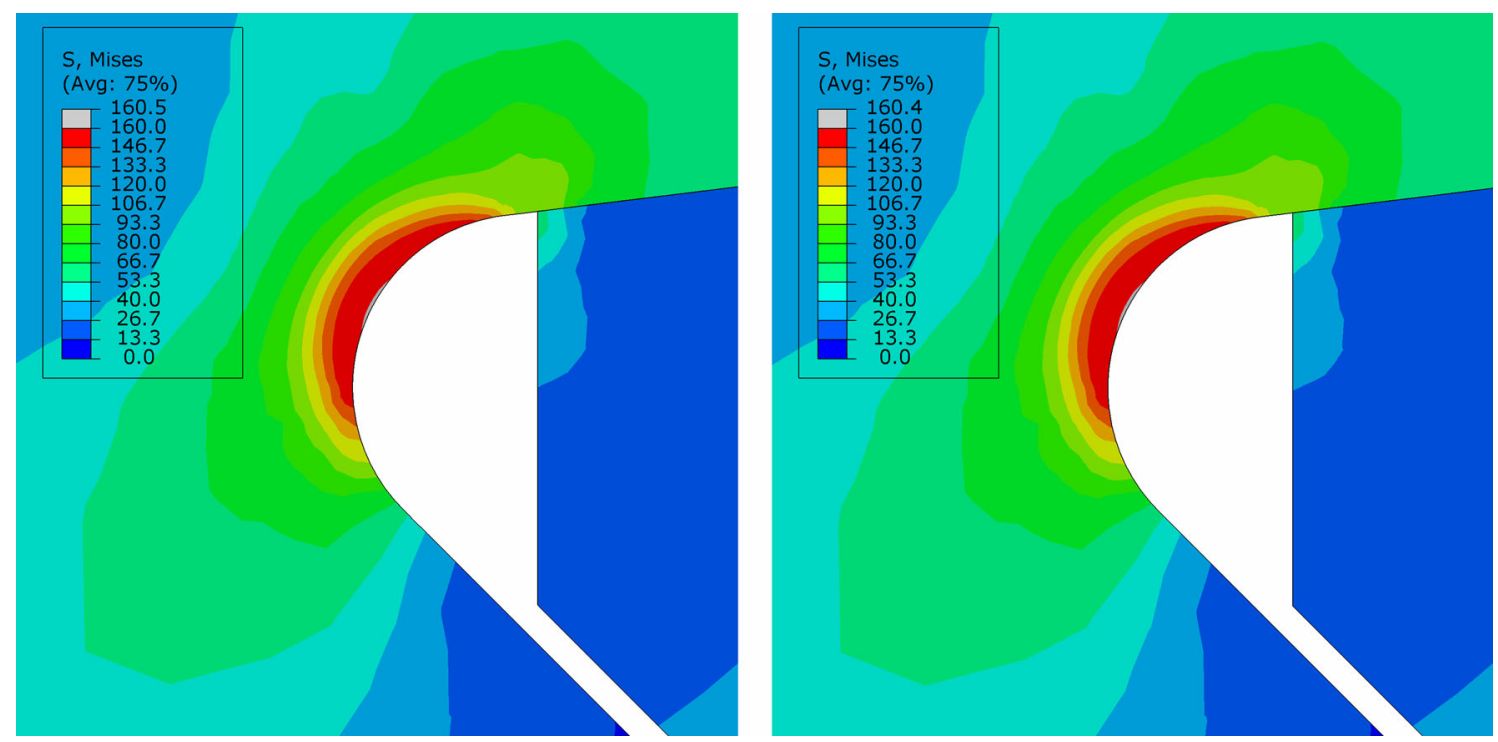

Fig. 5 Peak mises stresses with full piston load applied for the high-strength case. No difference in the stress state is observed whether or not the upper platen weld is intact. Similar results were found for the low-strength case (not pictured)
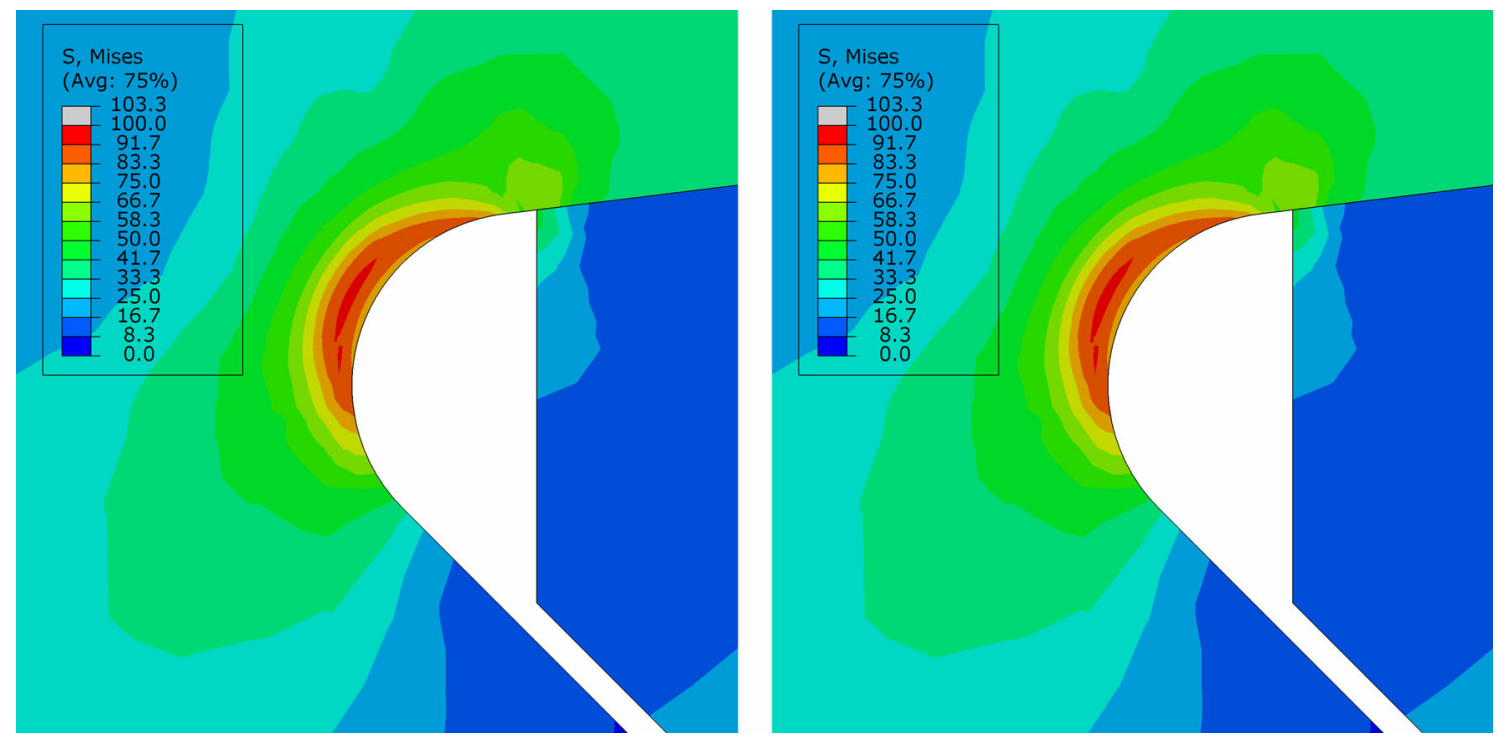

Fig. 6 Peak mises stresses with piston load being removed for the high-strength case. No difference in the stress state is observed whether or not the upper platen weld is intact. Similar results were found for the low-strength case (not pictured)

nut, representing the changes to the stress state as a result of the as-built condition of the forge press. No change in the peak Mises stresses was observed, neither with the piston load applied nor after it was removed, but an increase in the cyclic mean stress (and the corresponding decrease in the peak cyclic alternating stress) was observed for the minimum-strength cases. A similar change of the cyclic stresses was observed in the maximum-strength case, but a larger increase in the peak Mises stress was observed with the piston load being removed.
The largest change in stress state was observed when no preload was applied to the tie rod. Similar peak Mises stresses were observed when the piston load was applied, but a substantial decrease in the peak Mises stress was observed with the piston load being removed, particularly for the maximum-strength case. A substantial reduction in the cyclic mean stress (and the corresponding increase in the cyclic alternating stress) was observed in both models. No effect of the presence of a crack in the upper platen was observed in either case. 

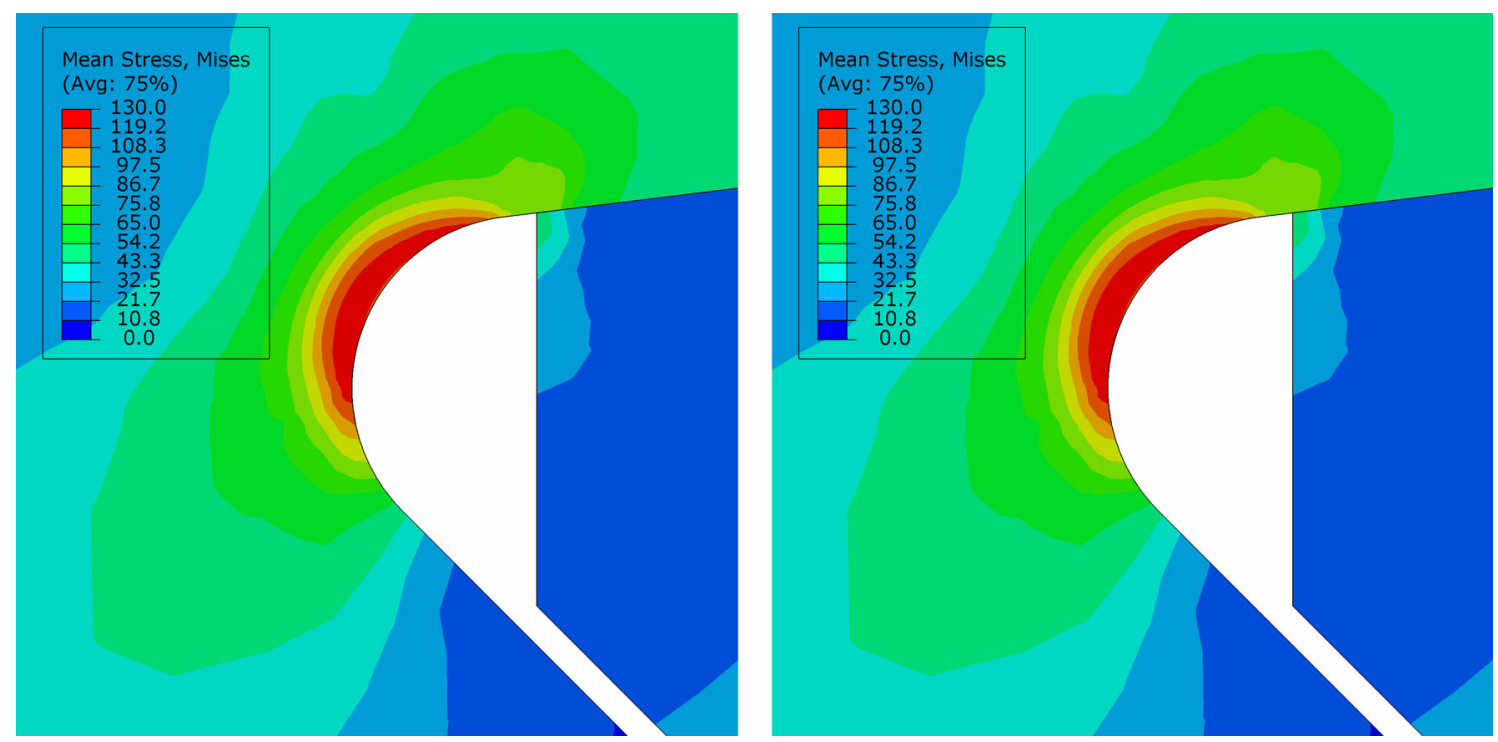

Fig. 7 Cyclic mean stresses for the high-strength case. No difference in the stress state is observed whether or not the upper platen weld is intact. Similar results were found for the low-strength case (not pictured)
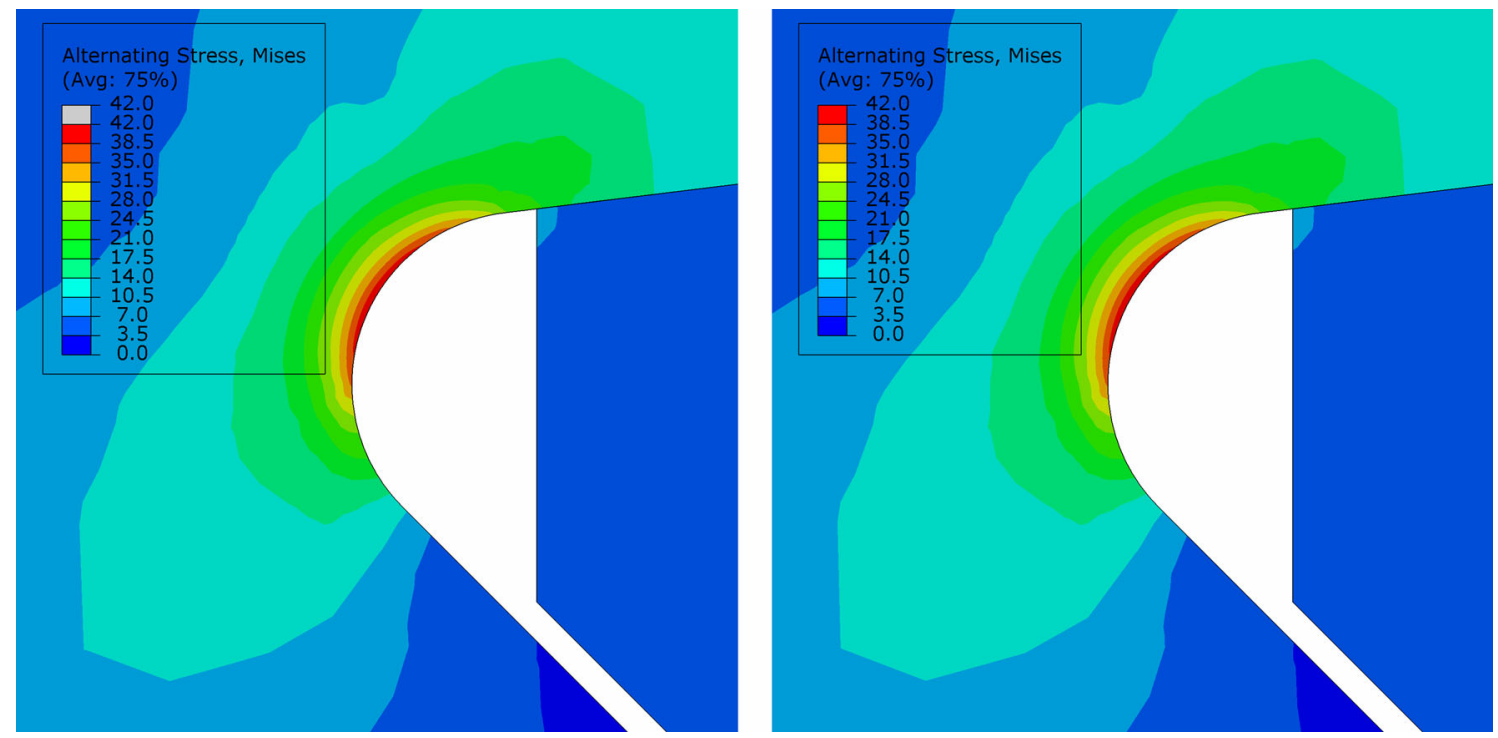

Fig. 8 Cyclic alternating stresses for the high-strength case. No difference in the stress state is observed whether or not the upper platen weld is intact. Similar results were found for the low-strength case (not pictured)

\section{Discussion}

The influence of the mechanical properties of the SW tie rod (higher strength, ultimately failed) and the NE tie rod (lower strength, no damage reported) was investigated by comparing the cyclic loading behavior of both models to the constant-lifetime fatigue data available for AISI 4340. Figure 9 shows the results for both models. As is apparent from Fig. 9, the data for the lower-strength model fall below the curve for a projected 10,000,000-cycle life, while the higher-strength model data fall between the 10,000-cycle and 100,000-cycle curves. These results are consistent with the observed behavior, wherein the SW tie rod failed after approximately 8 months in service, while no damage was observed in the NE tie rod.

The measured misalignment of the hydraulic nut seats may have played a contributory role in this failure by inducing bending stresses in the tie rods. Figure 10 shows the constant-lifetime fatigue analysis incorporating the results for the misaligned nut faces. As can be seen from Fig. 10, a small change in the fatigue behavior is expected as a result of this misalignment, though as a result of the 


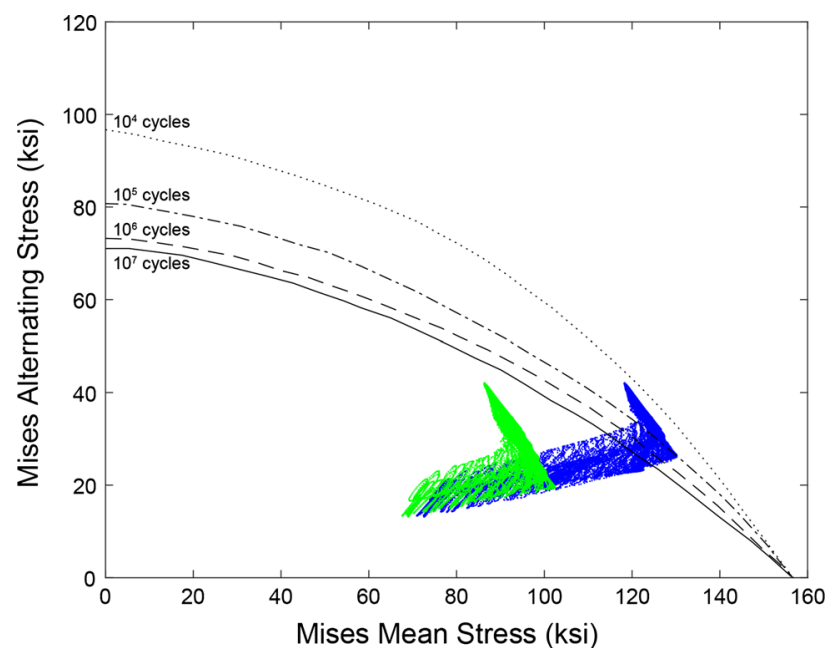

Fig. 9 Constant-lifetime fatigue behavior of low-strength (green) and high-strength (blue) models. Constant-lifetime fatigue curves for AISI-SAE 4340 alloy steel (bar) hardened and tempered to a tensile strength of $150 \mathrm{ksi}$ are shown for comparison [7]. A much shorter life is expected for the higher-strength tie rod

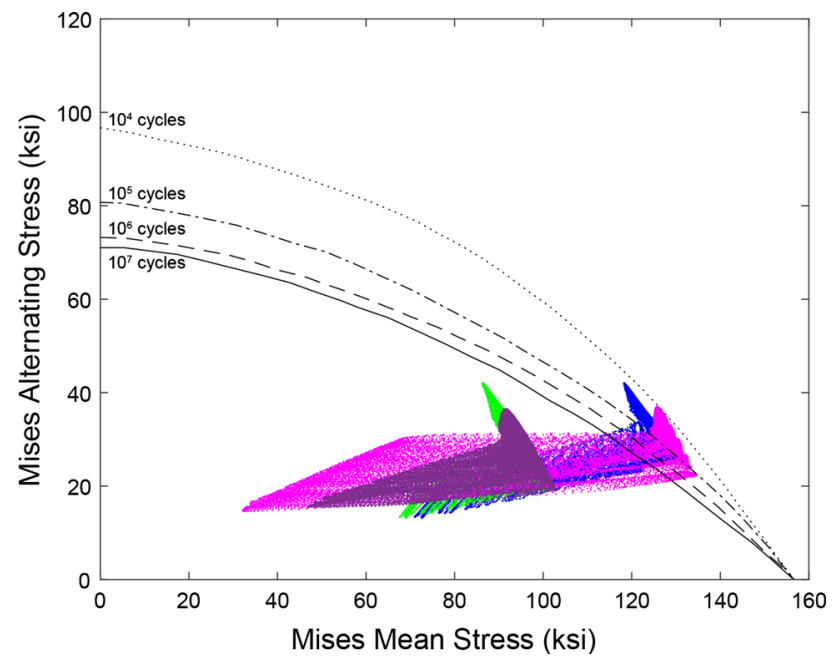

Fig. 10 Constant-lifetime fatigue behavior of low-strength (purple) and high-strength (pink) models incorporating the as-built misalignment of the hydraulic nut faces on the upper platen. For comparison, the as-designed data for the low-strength (green) and high-strength (blue) cases from Fig. 9 are repeated. Constant-lifetime fatigue curves for AISI-SAE 4340 alloy steel (bar) hardened and tempered to a tensile strength of $150 \mathrm{ksi}$ are shown for comparison [7]. Misalignment of the nut faces slightly reduces the expected fatigue lifetime

higher cyclic mean stresses slightly lower lives may be expected. This effect was more noticeable for the higherstrength case (i.e., the SW tie rod, which failed).

A much larger influence was seen as a result of tie rod preload, as shown in Fig. 11. A substantially shorter fatigue life was predicted for the zero-preload case than for either the as-designed or the as-manufactured (misaligned) cases; however, comparison of the 1,000,000-cycle curves

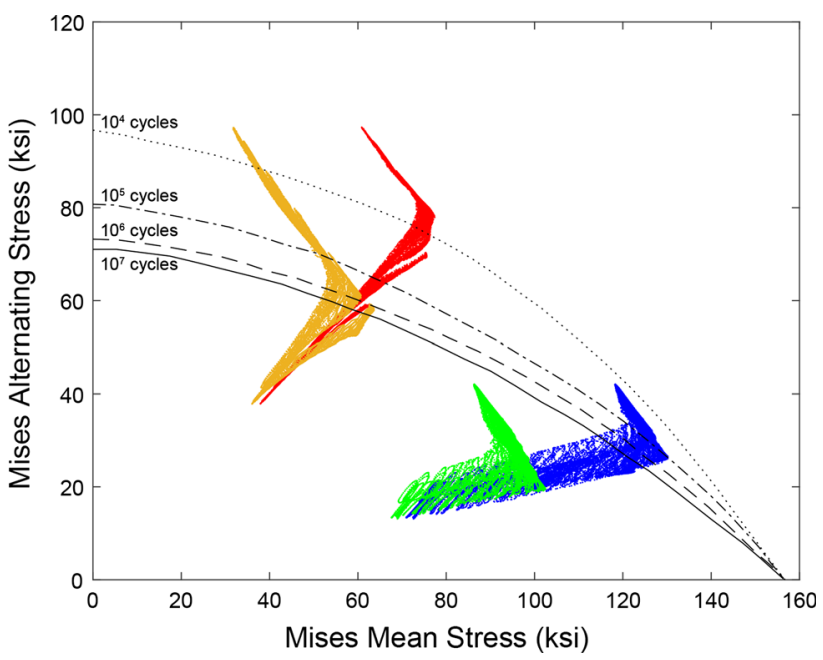

Fig. 11 Constant-lifetime fatigue behavior of low-strength (orange) and high-strength (red) zero-preload models. For comparison, the asdesigned data for the low-strength (green) and high-strength (blue) cases from Fig. 9 are also included. Constant-lifetime fatigue curves for AISI-SAE 4340 alloy steel (bar) hardened and tempered to a tensile strength of $150 \mathrm{ksi}$ are shown for comparison [7]. Lower preloads substantially reduce the expected fatigue lifetime

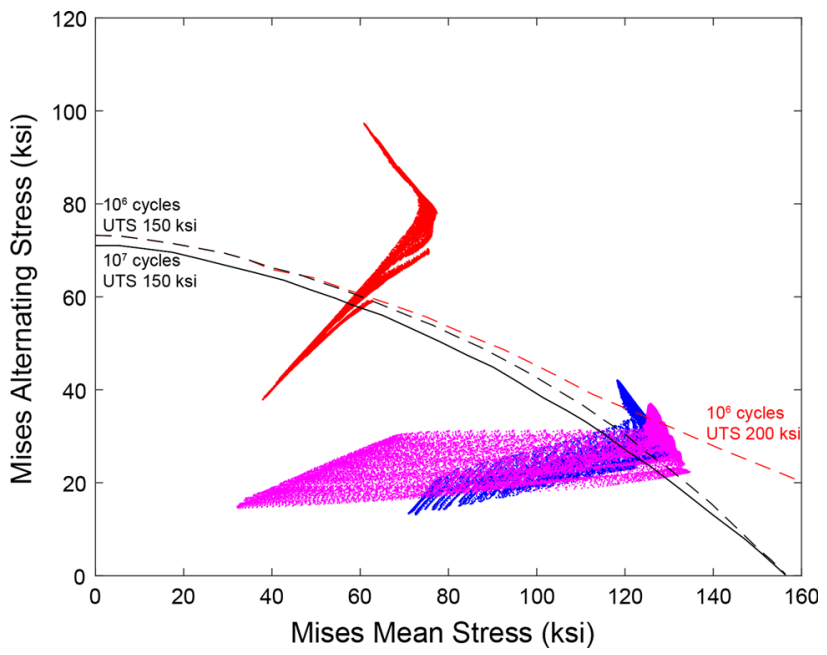

Fig. 12 Constant-lifetime fatigue behavior of high-strength models as designed (blue) incorporating the as-built misalignment of the hydraulic nut faces on the upper platen (pink) and with zero preload on the tie rod (red). Constant-lifetime fatigue curves for AISI-SAE 4340 alloy steel (bar) hardened and tempered to a tensile strength of $150 \mathrm{ksi}$ (black) and $200 \mathrm{ksi}$ (red) are shown for comparison [7]. While a higher strength results in a longer fatigue life for a give stress state, the SW tie rod would not have been expected to survive $1,000,000$ cycles, even in the as-designed state

for AISI 4340 hardened and tempered to a tensile strength of 150 or $200 \mathrm{ksi}$ (Fig. 12) suggests that the higher strength of the SW tie rod would have resulted in a longer fatigue life for a given stress state, though even with the higher strength the as-designed SW tie rod would be expected to last less than 1,000,000 cycles. 


\section{Conclusions}

Material properties played a critical role in this failure. The higher-than-specified strengths of two of the tie rods led to higher stresses at the thread roots, which ultimately led to premature failure of the tie rods. Comparison of the calculated stresses with the constant fatigue life behavior for AISI 4340 indicates that even as designed, the higher strength of the SW tie rod meant that a fatigue lifetime of less than $1,000,000$ cycles was expected.

Other issues observed in the as-failed forge press likely played a small role in this failure. Weld cracks in the upper platen (if they existed pre-failure) had little or no impact, as no difference in the stress state was observed whether or not the cracks were modeled in the FEM analysis. Similarly, misalignment of the hydraulic nut faces on the upper platen in and of itself did not greatly impact the stresses in the tie rods. Improper pre-tensioning of the tie rods could have greatly affected the stresses and ultimately the anticipated life.

Open Access This article is distributed under the terms of the Creative Commons Attribution 4.0 International License (http:// creativecommons.org/licenses/by/4.0/), which permits unrestricted use, distribution, and reproduction in any medium, provided you give appropriate credit to the original author(s) and the source, provide a link to the Creative Commons license, and indicate if changes were made.

\section{References}

1. Standard Test Methods for Chemical Analysis of Tool Steels and Other Similar Medium- and High-Alloy Steels. ASTM E35293(2006) ASTM International 2006

2. Standard Test Methods for Chemical Analysis of Carbon Steel, Low-Alloy Steel, Silicon Electrical Steel, Ingot Iron, and Wrought Iron. ASTM E350-12, ASTM International 2012

3. Standard Specification for Pressure Vessel Plates, Carbon Steel, for Moderate- and Lower-Temperature Service. ASTM A516/ A516 M-10, ASTM International 2010

4. Standard Specification for Quenched and Tempered VacuumTreated Carbon and Alloy Steel Forgings for Pressure Vessels. ASTM A508/A508 M-05 ${ }^{\varepsilon 1}$, ASTM International 2005

5. Standard Test Methods for Tension Testing of Metallic Materials. ASTM E8/E8 M-11, ASTM International 2011

6. Standard Test Methods for Notched Bar Impact Testing of Metallic Materials. ASTM E23-12, ASTM International 2012

7. H.E. Boyer, Atlas of Fatigue Curves (American Society for Metals, 1986) 